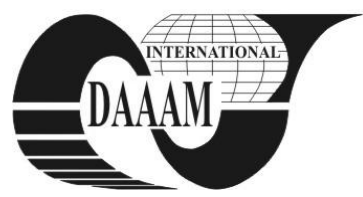

\title{
MODEL OF TOTAL COSTS FOR DETERMINING THE OPTIMAL CAPACITY OF THE CONTAINER TERMINAL IN PORT OF RIJEKA USING THE QUEUING THEORY
}

JURJEVIC, M[ia]

\begin{abstract}
The goal of this paper is to show that the implementation of the queuing theory could set an optimal capacity of the port container terminal, or a combination of the number of berths and cranes per berth with the minimum costs for the given traffic. The container terminal is a system composed of a specific number of mutually depending subsystems so the optimal capacity of the terminal is reduced to the calculation of the optimal number of berths. The optimal solution was received by applying a model of total costs, based on the queuing theory. The results are a basis for bringing adequate business decisions. The model is tested on an example of container terminal Brajdica in Port of Rijeka

Key words: queuing theory, optimal capacity, cost model, container terminal, port of Rijeka
\end{abstract}

\section{INTRODUCTION}

The problem of determining optimal capacity of the port container terminal is reduced to calculating an optimal number of berths, since the capacity of the berth determines the necessary capacity of the other subsystems of the port container terminal and thereby the throughput the container terminal.

Only few researchers have proposed quantitative models that support decision-making in risky and uncertain situations (Teimoury et al., 2011).

The container terminal should handle with the reserve capacity for cases of daily and monthly maximal traffic so the containers can at any moment be reloaded, but these capacity reserves would reduce the usage degree of the terminal, and also would increase a portion of fixed charges in its activity. This paper shows a model of costs and how its application determines the combination of number of berths and cranes on the berth with the least costs (Mendoza et al., 2009) for the given terminal traffic.

\section{MODEL OF TOTAL COSTS OF PORT OF RIJEKA CONTAINER TERMINAL}

The cost model of the container terminal Brajdica is presented with the function of total port costs $(C)$ which includes berths costs $\left(C_{b}\right)$, costs of container cranes $\left(C_{d}\right)$, costs of transport-handling equipment $\left(C_{p p}\right)$, crane operator costs $\left(C_{l d}\right)$, operator costs $\left(C_{l p}\right)$, stacking area costs $\left(C_{w h}\right)$, costs of ship stay in the port $\left(C_{W}\right)$ and cargo costs $\left(C_{Q}\right)$ (Zenzerovic et al., 2001).

\subsection{Berths costs}

The berth costs depend on the number of berths $(S)$ and unit cost per berth $\left(c_{h}\right)$, calculated with the formulas (Zenzerovic et al., 2011):

$$
C_{b}=S \cdot c_{b}
$$

$$
c_{b}=\left[B_{0} \cdot \frac{i(1+i)^{N_{b}}}{(1+i)^{N_{b}-1}}+M_{b}\right] \cdot \frac{1}{365 \cdot 24}
$$

\subsection{Costs of container cranes}

The total costs of container cranes depends on the number of berths $(S)$, the number of cranes per berth $(d)$ and costs per crane $\left(c_{d}\right)$. The costs are obtained with the formulas:

$$
\begin{gathered}
C_{d}=S \cdot d \cdot c_{d} \\
c_{d}=\left[D_{0} \cdot \frac{i(1+i)^{N_{d}}}{(1+i)^{N_{d}}-1}+M_{d}\right] \cdot \frac{1}{365 \cdot 24}
\end{gathered}
$$

\subsection{Costs of transport-handling equipment}

The costs of transport-handling equipment depend on the number of transport-handling equipment $(p)$ and unit cost per equipment $\left(c_{p p}\right)$ They are calculated with the formulas:

$$
\begin{gathered}
C_{p p}=p \cdot c_{p p} \\
c_{p p}=\left[P_{0} \cdot \frac{i(1+i)^{N_{p p}}}{(1+i)^{N_{p p}}-1}+M_{p p}\right] \cdot \frac{1}{365 \cdot 24}
\end{gathered}
$$

\subsection{Costs of human resource}

Total costs of human resource contain total costs of crane operators $\left(C_{l d}\right)$ and total costs of operators $\left(C_{l p}\right)$, that are calculated with the next formulas:

$$
\begin{gathered}
C_{l d}=\lambda \cdot d \cdot t_{l d} \cdot c_{l d} \\
C_{l p}=n \cdot c_{l p}
\end{gathered}
$$

Operating time for crane operators $\left(t_{l d}\right)$, or the duration of ship reload (h/crane/ship) is calculated with formula:

$$
t_{l d}=\frac{x \cdot y}{d^{f}}
$$

If $t_{l d}$ is less than the minimal operating time in each shift, then the port pays minimal hours, and not the real value $t_{l d}$. That means that $t_{l d}=\max \left(t_{l d}, t_{\min }\right)$, where $t_{\min }$ stands for the minimal duration of working shift.

The intensity of ship arrivals $(\lambda)$, presents the average number of dockings, or the arrival of ships to the container terminal. 


\subsection{Stacking area costs}

The stacking area costs present a product of necessary stacking area capacity $\left(k_{w h}\right)$, size of stacking surface per container $(a)$ and cost per unit of stacking surface $\left(c_{w h}\right)$.

The amount of costs is obtained by using the next formulas:

$$
\begin{gathered}
C_{w h}=k_{w h} \cdot a \cdot c_{w h} \\
k_{w h}=\lambda \cdot x \\
c_{w h}=\left[W_{h 0} \cdot \frac{i(1+i)^{N_{w h}}}{(1+i)^{N_{w h}}-1}+M_{w h}\right] \cdot \frac{1}{365 \cdot 24}
\end{gathered}
$$

\subsection{Costs of ship stay}

The costs of ship stay are obtained with these formulas:

$$
\begin{gathered}
C_{W}=\lambda \cdot W \cdot c_{W} \\
\mu=1 /\left(t_{l d}+t_{m}\right) \varrho=\lambda / \mu \\
c_{W}=\left[W_{0} \cdot \frac{i(1+i)^{N_{W}}}{(1+i)^{N_{W}}-1}+M_{W}\right] \cdot \frac{1}{365 \cdot 24}
\end{gathered}
$$

\subsection{Cargo costs}

The total cargo costs depend on the intensity of ship arrival into the port $(\lambda)$, duration of ship stay in the port $(W)$, which among others depends on the number of berths, the number of cranes per berth and amount of cargo $(Q)$, the number of containers on the ship and the costs per container $\left(c_{Q}\right)$.

The total amount of cargo costs is calculated with the formula:

$$
C_{Q}=\lambda \cdot W \cdot Q \cdot c_{Q}
$$

\subsection{Total costs of container terminal Brajdica}

The function of total costs of the container terminal system has the form (Zenzerovic et al., 2001):

$$
C=C_{b}+C_{d}+C_{p p}+C_{l d}+C_{l p}+C_{w h}+C_{W}+C_{Q}
$$

where $C$ is the symbol for total costs of the port container terminal expressed in money units in the observed time unit, for example in $€ / \mathrm{h}$.

\begin{tabular}{|c|c|c|c|}
\hline Costs & $\mathrm{A}$ & $\mathrm{B}$ & $\mathrm{C}$ \\
\hline$C_{b}$ & 54.60 & 54.60 & 54.60 \\
\hline$C_{d}$ & 327.54 & 186.52 & 327.54 \\
\hline$C_{p p}$ & 80.70 & 53.80 & 80.70 \\
\hline$C_{l d+} C_{l p}$ & 179.15 & 120.61 & 186.05 \\
\hline$C_{w h}$ & 5664.00 & 5664.00 & 14180.76 \\
\hline$C_{W}$ & 179.24 & 430.29 & 837.76 \\
\hline$C_{Q}$ & 654.71 & 1591.50 & 4131.42 \\
\hline Total & 7139.94 & 8101.32 & 19798.83 \\
\hline
\end{tabular}

Tab. 1. Total costs of container terminal Brajdica $(€ / \mathrm{h})$

In order to find the optimal capacity of container terminal Brajdica, different variants are compared depending on the traffic and number of cranes per berth:
- Variant A - 2 berths, 3 cranes; two on the first and one on the second berth,

- Variant B - 2 berths, 2 cranes; one on the first and one on the second berth,

- Variant C - the expected traffic 300000 TEU, 2 berths; two cranes on first and one on the second berth, 400+ 100 TEU/ship.

To show the costs of the container terminal according to the existing traffic and capacity, the calculation of variant A analyses the present condition with two container cranes „Samsung" at the Kostrensko quay (SOUTH) and one container bridge „Metalna“" on Kostrensko quay (WEST).

With the application of variant $\mathrm{B}$, that also takes into account the momentary stacking area capacity of the terminal and achieved traffic in 2010 , but with the usage of one crane per berth, the costs of the cranes, transport-handling equipment and human resource are reduced, as expected.

In conditions of the existing traffic and terminal capacity, the optimal solution is variant $\mathrm{A}$ with two berths and three cranes.

Variant C covers the present technical-technological features of the container terminal, two cranes on the south berth and one on the west, with the expected traffic increase to 300 000 TEU.

The plan for extending the terminal predicts development of nearly $167000 \mathrm{~m}^{2}$ of port surface while after upgrading the container stacking surface with the existing $56100 \mathrm{~m}^{2}$ will increase to $103600 \mathrm{~m}^{2}$. After achieving the planned projects, the capacity of the container terminal Brajdica will be enabled to except nearly $500000 \mathrm{TEU}$ per year.

\section{CONCLUSION}

Based on the results, the conditions of the existing traffic and the capacity of the terminal the optimal solution is the variant with two berths and three cranes, which is the real situation on the terminal Brajdica.

However, if the present technical-technological features of the container terminal, compares to the expected traffic of 300 $000 \mathrm{TEU}$, then the given results show a significant increase of the total terminal costs, which is the result of the increasing ship, cargo and especially stacking costs.

The conclusion is that, considering the predicted traffic increase, it is necessary to finish the project for expanding the container terminal as soon as possible to speed up the reload operations on the terminal and reduce the ship waiting costs.

\section{REFERENCES}

Artalejo, J. R. \& Li, Q. L. (2011). Editorial for the special issue: Retrial Queues (WRQ'10). Operational Research, Vol. 11, No. 11, ISSN 12351-011-0121-7

Mendoza, G.; Sedaghat, M \& Yoon, K. P. (2009). Queuing Models To Balance Systems With Excess Supply The Clute Institute. International Business \& Economics Research Journal, Vol. 8, No.1, January, 2009

Teimoury, E.; Mazlomi, A. \& Khondabi, I. (2011). Optimizing Multi Supplier Systems with Fuzzy Queuing Approach: Case Study of SAPCO, Proceedings of the International MultiConference of Engineers and Computer Scientists Vol. II., IMECS 2011, March 16-18, Hong Kong ISSN: 2078-0958 2078-0966, ISBN: 978-988-19251-2-1 (Online)

Zenzerovic, Z.; Vilke, S. \& Jurjevic, M. (2011). Queuing theory in function of planning the capacity of the container terminal in port of Rijeka, Scientific Journal of Maritime Research, Vol.25, No.1, 45-69, ISSN 1332-0718

*** (2010) http://www.tel.fer.hr/_download/repository/ Predavanje5-Redovi_cekanja.pdf- Information networks, Accessed on: 24/08/2011 